U.S. Department of the Interior

U.S. Geological Survey

\title{
Digital aeromagnetic anomaly data from eastern-most Guyana
}

by

Herbert A. Pierce ${ }^{1}$, Natalka Backjinski ${ }^{2}$, and John-James Manes ${ }^{2}$

Open-File Report OF 95-590

This report is preliminary and has not been reviewed for conformity with U.S. Geological Survey editorial standards or with the North American Stratigraphic Code. Any use of trade, product, or firm names is for descriptive purposes only and does not imply endorsement by the U.S. Government. Although this program has been used by the U.S. Geological Survey, no warranty, expressed of implied, is made by the USGS as to the accuracy and functioning of the program and related program material, nor shall the fact of distribution constitute any such warranty, and no responsibility is assumed by the USGS in connection therewith.

1 Center for Inter-American Mineral Investigations, 210 E. 7th Street, Tucson, Arizona 85705

${ }^{2}$ University of Arizona, Tucson, Arizona 


\section{INTRODUCTION}

The Center for Inter-American Mineral Resource Investigations (CIMRI) supported distribution and analysis of geoscientific and mineral resource related information concerning Latin America. CIMRI staff digitized aeromagnetic data for eastern-most Guyana as part of a preliminary regional assessment of minerals in the Guyana Shield, South America. The data were digitized from 145 aeromagnetic contour maps at a scale of 1:50,000 and merged into a single digital data set. The data were used to examine the Precambrian shield, greenstone belts, and other tectonic boundaries as well as explore ideas concerning mineral deposits within the area. A subset of these digital data were presented to the Guyanan government during early 1995 (Pierce, 1994). This Open-File report, consisting of this text and seven (7) 3.5" IBM-PC compatible ASCII magnetic disks, makes the digital data available to the public. Information regarding the source of data and subsequent processing is included below.

The data were collected in Guyana by two contractors at different times. The first data were collected from 1962 to 1963. These data are several aeromagnetic surveys covering parts of 12 quadrangles funded by the United Nations and flown by Aero Service Corporation. The second and more extensive data set was collected from 1971 to 1972 by the Canadian International Development Agency flown by Terra Surveys Ltd. under a contract with the Geological Survey of Guyana. The Guyana Government published the data as contour maps that are available in Georgetown through the Guyana Government. Coverage extends from about $2^{\circ} 45^{\prime} \mathrm{N}$ to $8^{\circ} 30^{\prime} \mathrm{N}$ latitude and from $60^{\circ} 0^{\prime} \mathrm{W}$ to $57^{\circ} 0^{\prime} \mathrm{W}$ longitude (see Figure 1.). The contour maps were digitized at points where the magnetic contours intersect the flight lines.

The data files include XYZ ASCII files, XYZ binary files, ASCII grids, and binary "standard USGS" grids. There are four grids consisting of the following data types:

- unprojected raw data grid

- unprojected residual or International Geomagnetic Reference Field (IGRF) removed grid

- UTM projected residual (IGRF removed) grid

- UTM projected residual with a second order surface removed

These data files were transferred to 3.5" 1.44 megabyte floppy disks readable on IBM-compatible personal computers. These data are also available from the Department of Commerce National Geophysical Data Center'.

\section{NATURE AND CONTENTS OF THE 3.5" DISKS}

The data files span seven disks and are compressed. Files are stored using PKZIP and must be uncompressed and unspanned using the command: PKUNZIP -e a:Iguyana.zip *.* (or b:lguyana *.*

\footnotetext{
${ }^{1}$ Address: National Geophysical Data Center, NOAA, Code E/GCl, 325 Broadway, Boulder, CO 80303 U.S.A.,
} Phone 303-497-6826, Fax 303-497-6513. 
depending upon which drive letter is assigned to your 3.5" floppy disk drive). Once the files are unzipped they are ready for use.

\section{AEROMAGNETIC COVERAGE \\ INDEX MAP}

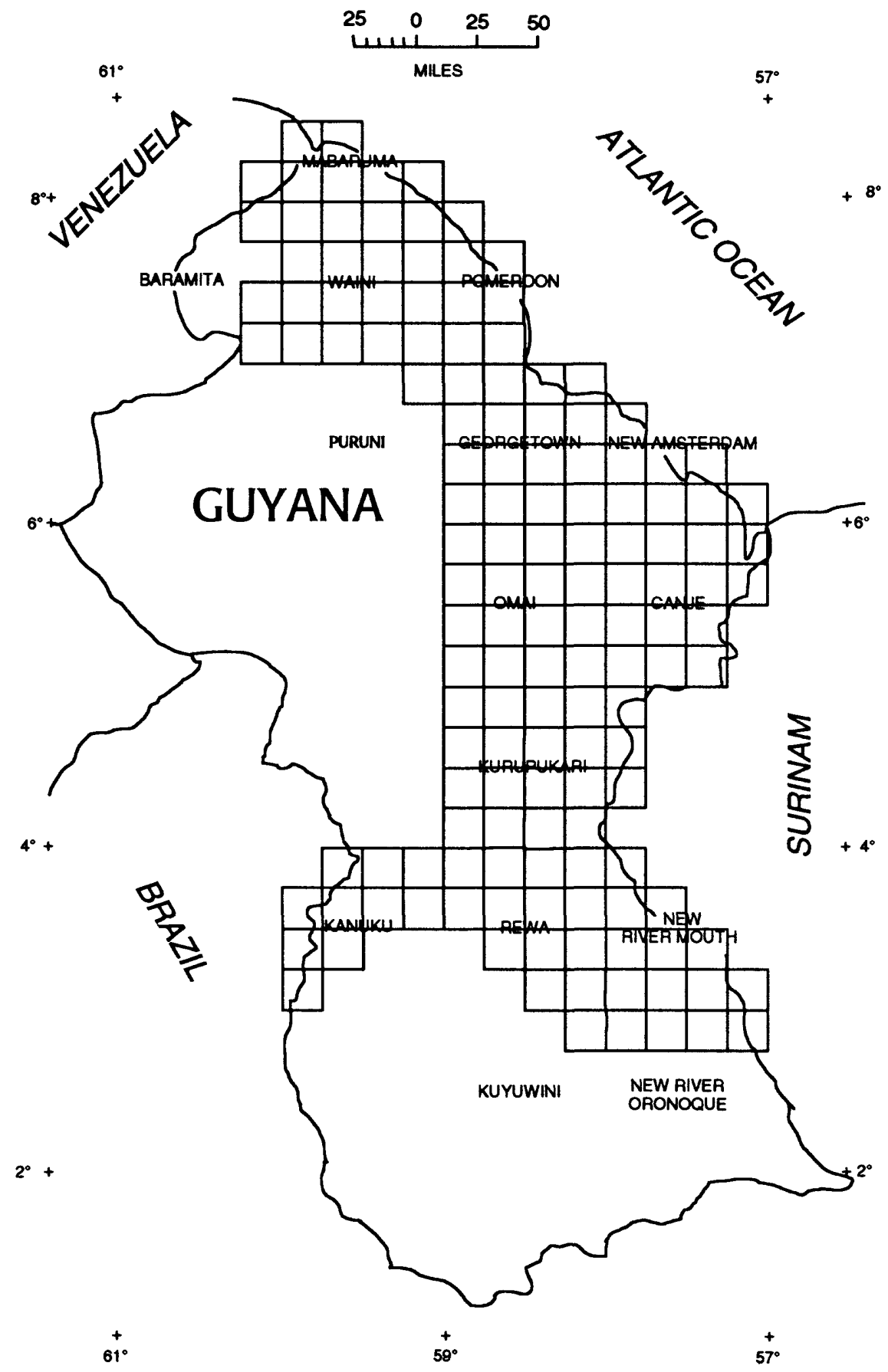

Figure 1. Map of aeromagnetic coverage showing the one hundred fourty five 1:50,000 scale aeromagnetic maps. 
The compression-extraction program PKUNZIP is included with the disks. The user will need 43 megabytes of hard disk space for the data, source code, executable, and PKZIP files after extracting the files from the 3.5" diskettes. There are a total of 20 data and source code files on the disks. After they are uncompressed the user should have a grand total of 22 files (count includes PKZIP and PKUNZIP).

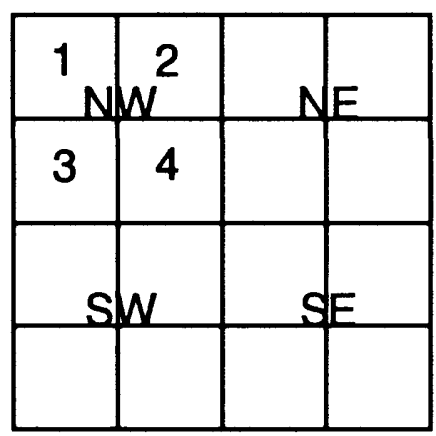

Figure 2. The orientation and labeling scheme used to name the 1:50,000 scale Guyana aeromagnetic maps from the 1:200,000 scale quadrangles. For example; Omai NW1 would be the upper left most 1:50,000 quadrangle if figure 2 representes the 1:200,000 scale Omai quadrangle

Common characteristics of the data files include mean ground clearance of the flight lines of 305 meters, mean flight line spacing of 1000 meters, and mean control line spacing of 40 kilometers. The projected aeromagnetic grids have a 1.25 kilometer grid interval. The unprojected aeromagnetic grids have a 0.009 degree grid interval. For most purposes, the "USGS standard" grids are the only data files a user will need. FORTRAN 77 code and executable files of selected computer programs included with this release can read the above-mentioned files. A more complete set of programs to manipulate the data are available on CD-ROM published as U.S. Geological Survey digital data series DDS-9 (Phillips 1993).

Projected grids are in Universal Transverse Mercator (UTM) coordinates. The central meridian is -60 degrees (minus sign indicates west longitude), and the base latitude is 0 degrees. Units are in kilometers with no false easting or northing. Unprojected files are in decimal degrees and the grid size is 0.009 degrees.

The three data areas (blue, brown, and green) were grided separately then merged into one grid. Several techniques were used to stitch the grids into a single file. See Tables 1 to 3 for listings of various quadrangles in each data set. Though extreme care was exercised to produce a seamless product, problems with merging dissimilar datum exist. For example, when grids are fitted with a north-south preference the east-west fit suffers and visa versa. I have included the unaltered files for each area so that the user can regrid and remerge the data with state of the art commercial programs. 
$\begin{array}{lllll}\text { BROWN } & \text { NW } & \text { NE } & \text { SW } & \text { SE }\end{array}$

\begin{tabular}{|c|c|c|c|c|c|c|c|c|c|c|c|c|c|c|c|c|}
\hline (northernmost Guyana) & 1 & 2 & 3 & 4 & 1 & 2 & 3 & 4 & 1 & 2 & 3 & 4 & 1 & 2 & 3 & 4 \\
\hline MABARUMA & & & & & & & & & $\mathbf{X}$ & $\mathrm{X}$ & $\mathrm{X}$ & $\mathrm{X}$ & & & $\mathbf{X}$ & $\mathbf{X}$ \\
\hline WAINI & $\mathrm{X}$ & $\mathbf{X}$ & & & $\mathbf{x}$ & $\mathbf{X}$ & $\mathrm{X}$ & $X$ & & & & & $\mathrm{X}$ & $\mathrm{X}$ & $\mathrm{X}$ & $\mathrm{X}$ \\
\hline POMEROON & $\mathbf{X}$ & & $\mathrm{X}$ & $\mathbf{x}$ & & & & & $\mathrm{X}$ & $\mathbf{X}$ & $\mathrm{X}$ & $\mathrm{X}$ & & & & \\
\hline GEORGETOWN & $\mathbf{X}$ & $\mathbf{X}$ & & & $X$ & $\mathrm{X}$ & $\mathbf{X}$ & $\mathbf{X}$ & & & & & $\mathrm{X}$ & $\mathbf{X}$ & & $1 / 2$ \\
\hline NEW AMSTERDAM & & & $\mathbf{X}$ & & & & & & $\mathrm{X}$ & $\mathrm{X}$ & $\mathrm{X}$ & $\mathrm{X}$ & $\mathrm{X}$ & & $X$ & $\mathbf{X}$ \\
\hline CANJE & $\mathbf{X}$ & $\mathbf{X}$ & & $\mathbf{X}$ & $\mathbf{X}$ & $\mathbf{X}$ & $\mathbf{X}$ & $\mathbf{X}$ & & & & & & & & \\
\hline
\end{tabular}

Table 1. The area designated brown covers north-east Guyana. The Xs denote full quadrangle coverage over land, the $1 / 4,1 / 2$, and $3 / 4$ symbols denote approximate coverage provided from the 1:50,000 scale aeromagnetic maps.

$\begin{array}{llll}\text { BLUE } & \text { NW } & \text { NE } & \text { SW }\end{array}$

\begin{tabular}{|c|c|c|c|c|c|c|c|c|c|c|c|c|c|c|c|c|}
\hline (southeast Guyana) & $\mathbf{1}$ & 2 & 3 & 4 & 1 & 2 & 3 & 4 & 1 & 2 & 3 & 4 & 1 & 2 & 3 & 4 \\
\hline BARAMITA & & & & & & $1 / 2$ & & & & & & & & $1 / 2$ & & $1 / 2$ \\
\hline WAINI & & & $\mathbf{X}$ & $\mathbf{X}$ & & & & & $\mathbf{X}$ & $\mathrm{x}$ & $\mathbf{x}$ & $\mathbf{X}$ & & & & \\
\hline PURUNI & & & & & & $1 / 2$ & & & & & & & & & & \\
\hline GEORGETOWN & & & $3 / 4$ & & & & & & $1 / 2$ & $\mathrm{x}$ & $1 / 2$ & $\mathrm{X}$ & & & $\mathrm{X}$ & $1 / 2$ \\
\hline OMAI & $1 / 2$ & $\mathbf{X}$ & $1 / 2$ & $\mathbf{X}$ & $\mathbf{X}$ & $\mathbf{X}$ & $\mathbf{X}$ & $\mathbf{X}$ & $3 / 4$ & $\mathbf{X}$ & $X$ & $\mathbf{X}$ & $\mathbf{X}$ & $\mathbf{X}$ & $\mathrm{X}$ & $\mathrm{X}$ \\
\hline CANJE & & & $\mathrm{X}$ & & & & & & $\mathrm{X}$ & $\mathrm{X}$ & $\mathrm{X}$ & $\mathrm{X}$ & $\mathrm{X}$ & $\mathrm{X}$ & & \\
\hline KURUPUKARI & $X$ & $\mathbf{X}$ & $\mathbf{X}$ & $\mathbf{X}$ & $\mathbf{X}$ & $\mathbf{X}$ & $\mathbf{X}$ & $\mathrm{X}$ & $\mathbf{X}$ & $\mathbf{X}$ & $\mathbf{X}$ & $\mathbf{X}$ & $\mathrm{X}$ & $\mathbf{X}$ & $\mathrm{X}$ & $\mathrm{X}$ \\
\hline KANUKU & & $\mathbf{X}$ & $\mathbf{X}$ & $\mathbf{X}$ & $\mathbf{X}$ & $\mathrm{X}$ & $\mathbf{X}$ & $\mathbf{X}$ & $\mathrm{X}$ & $1 / 2$ & $1 / 2$ & & & & & \\
\hline REWA & $\mathbf{X}$ & $\mathbf{X}$ & $\mathbf{X}$ & $\mathbf{X}$ & $\mathbf{X}$ & $\mathrm{X}$ & $X$ & $\mathrm{X}$ & & $\mathrm{X}$ & & & $X$ & $\mathrm{X}$ & $X$ & $X$ \\
\hline NEW RIVER MOUTH & & & $\mathbf{X}$ & $X$ & & & & & $X$ & $\mathbf{X}$ & $\mathrm{X}$ & $X$ & $X$ & & $\mathrm{X}$ & $\mathrm{X}$ \\
\hline
\end{tabular}

KUYUWINI

$\mathbf{X}$

NEW RIVER ORONOQUE $\quad \mathrm{X} \quad \mathrm{X} \quad \mathrm{X} \quad \mathrm{X}$

Table 2. The area designated blue covers eastern Guyana. The Xs denote full quadrangle coverage over land, the $1 / 4,1 / 2$, and $3 / 4$ symbols denote approximate coverage provided from the $1: 50,000$ scale aeromagnetic maps. 


\begin{tabular}{|c|c|c|c|c|c|c|c|c|c|c|c|c|c|c|c|c|}
\hline \multirow{2}{*}{$\begin{array}{c}\text { GREEN } \\
\text { (parts of central Guyana) } \\
\end{array}$} & \multicolumn{4}{|c|}{ NW } & \multicolumn{4}{|c|}{ NE } & \multicolumn{4}{|c|}{ SW } & \multicolumn{4}{|c|}{ SE } \\
\hline & 1 & 2 & 3 & 4 & 1 & 2 & 3 & 4 & 1 & 2 & 3 & 4 & 1 & 2 & 3 & 4 \\
\hline BARAMITA & & & & & & $1 / 2$ & & & & & & & & & $1 / 2$ & $1 / 2$ \\
\hline PURUNI & & & & & & $1 / 4$ & & & & & & & & & & \\
\hline OMAI & $1 / 2$ & & $1 / 2$ & & & & & & $1 / 4$ & & & & & & & \\
\hline KANUKU & & & & & & & & & & $1 / 2$ & $1 / 2$ & & & & & \\
\hline
\end{tabular}

Table 3. The area designated green covers parts of quadrangles in central Guyana. The $1 / 4,1 / 2$, and $3 / 4$ symbols denote approximate coverage provided from the 1:50,000 scale aeromagnetic maps.

\section{Files 1-3 (BLUE, BROWN, AND GREEN.DAT):}

Files with the form filename.DAT are the XYZ ASCII data output from the digitizer generated by hand-digitizing the intersection of contour lines and flight lines. The XYZ ASCII data file is in the form of (3F16.6), longitude, latitude, and magnetic field. Longitude and latitude are in decimal degrees and the magnetic field is in gammas (nT).

The DAT files are separate because of the different times and parameters used during the collection of the data sets. Blue files use a January 1968 magnetic variation and were flown during 1971 to 1972 . Brown files use a January 1970 magnetic variation and were flown during 1971 to 1972 . Green files use a 1960 magnetic variation, were flown during 1962 to 1963, and have an arbitrary datum removed from the total field.

\section{Files 4-6 (BLUE, BROWN, or GREEN.XYZ):}

Files with the form filename. $\mathrm{XYZ}$ are the binary $\mathrm{XYZ}$ files identical to those in files 1-3 above. The files are included because some of the programs released in DDS-9 (Phillips 1993) require binary $\mathrm{XYZ}$ files.

\section{File 7 GUYRAW.ASC:}

The file GUYRAW.ASC is the ASCII version of the USGS standard grid file for the raw magnetic field data from northern Guyana. When converted to binary using program ASCII2SF and examined using program ID, the following output describes the grid:

1) Enter input file name:

2) * Guyana Aeromagnetics, unfiltered and unadulterated

3) $\operatorname{minc}$

4) $\mathrm{ncol}=349 \quad$ nrow $=629 \quad \mathrm{nz}=1$ 
5) $\mathrm{x} 0=-60.24560 \mathrm{dx}=.9000000 \mathrm{E}-02 \quad \mathrm{y} 0=2.750010 \quad \mathrm{dy}=.9000000 \mathrm{E}-02$

6) Stop - Program terminated.

where:

line $1=$ command line

line $2=$ file title

line 3 = name of the program used to generate grid

line $4=$ number of columns, number of rows, and number of $z$

line $5=x$-origin, $x$-spacing, y-origin, and y-spacing (in degrees)

line 6 = program termination

File 8 GUY-IGRF.ASC:

ASCII version of USGS standard grid file containing residual magnetic field data. When converted to binary using program ASCII2SF and examined using program ID, the following output describes the grid:

Enter input file name:

* Guyana Aeromagnetics, minus IGRF

addgrd

$\mathrm{ncol}=345 \quad$ nrow $=629 \quad \mathrm{nz}=1$

$\mathrm{x} 0=-60.24560 \mathrm{dx}=.9000000 \mathrm{E}-02 \quad \mathrm{y} 0=2.750010 \mathrm{dy}=.9000000 \mathrm{E}-02$

Stop - Program terminated.

\section{File 9 GUYRESP.ASC:}

ASCII version of USGS standard grid file containing the UTM projected residual magnetic field (IGRF removed). When converted to binary using program ASCII2SF and examined using program ID, the following output describes the grid:

Enter input file name:

* Guyana Aeromagnetics UTM projected and IGRF removed

prjgrd

iproj $=2$ central merid. $=-85.000000$ base lat. $=.000000$ 
ncol $=276 \quad$ nrow $=501 \quad n z=1$

$x 0=-27.29844 \quad d x=1.250000 \quad y 0=303.9417 \quad d y=1.250000$

Stop - Program terminated.

File 10 GUY2ND.ASC:

ASCII version of USGS standard grid file containing the UTM projected residual magnetic field (IGRF removed) with a second order surface removed. When converted to binary using program ASCII2SF and examined using program ID, the following output describes the grid:

Enter input file name:

* Guyana Aeromag, UTM, minus IGRF \& 2nd order surface

surfit

ncol $=276 \quad$ nrow $=501 \quad n z=1$

$\mathrm{x} 0=-27.29844 \mathrm{dx}=1.250000 \quad \mathrm{y} 0=303.9417 \quad \mathrm{dy}=1.250000$

Stop - Program terminated.

\section{File 11 GUYRAW.GRD:}

Binary version of the USGS standard grid file containing unprojected raw magnetic field data. For file specifications the user can run the program ID or read the listing above for file GUYRAW.ASC.

\section{File 12 GUY-IGRF.GRD:}

Binary version of the USGS standard grid file containing the unprojected residual (IGRF removed) magnetic field data. For file specifications the user can run the program ID or read the listing above under GUY-IGRF.ASC. 


\section{File 13 GUYRESP.GRD:}

Binary version of the USGS standard grid file containing the UTM projected residual (IGRF removed) magnetic field data. For file specifications the user can run the program ID or read the listing above under GUYRESP.ASC.

File 14 GUY2ND.GRD:

Binary version of the USGS standard grid file containing the UTM projected residual (IGRF and a second order residual field removed) magnetic field data. For file specifications the user can run the program ID or read the listing above under GUY2ND.GRD.

File 15-16. ASCII2SF.EXE and ASCII2SF.FOR

FORTRAN program and source code to convert ASCII file version of USGS standard grid to binary version. For specifications of standard grid file, see Appendix 1.

File 17-18 SF2ASCII.EXE and SF2ASCII.FOR

FORTRAN program and source code to convert binary file version of USGS standard grid to ASCII version. For specifications of standard grid file, see Appendix 1.

\section{File 19-20 ID.EXE and ID.FOR}

FORTRAN program and source code to print identification, grid parameters, and minimum and maximum of USGS standard grid.

\section{File 21 GUYAERO.TXT}

The ASCII text copy of this report. Because of limitations inherent in the DOS text format, maps and tables included in the official open-file report are generally not reproducable. I recommend that the open-file report paper copy be acquired. 


\section{APPENDIX 1}

Specifications of USGS standard grid (Cordell and others, 1992):

GRID DATA: (Referred to as "standard file" in some of the programs). Gridded input and output to all the programs are in standardized binary grid format, often with the file name suffix ".grd". Currently, the standard grid applies only to real-valued scalar data in rectangular cells. The grid file consists of a header record followed by one record for each row of data. Row 1 is the first row stored. Origin is in the lower left or southwest corner, starting at row 1, column 1. Row numbers increase upward or northward; column numbers increase to the right or eastward.

Header record (23 4-byte words):

id: 56 ASCII characters of identification

(character*56). pgm: 8 ASCII characters identifying creating program (sometimes); character*8.

ncol: number of columns (integer).

nrow: number of rows (integer).

$\mathrm{nz}$ : number of words per data element.

Normally $\mathrm{nz}=1$. (integer).

$\mathrm{x} 0$ : position of first column of data, in

$\mathrm{km}($ real*4).

$\mathrm{dx}$ : delta $\mathrm{x}$, spacing interval of columns, in $\mathrm{km}\left(\mathrm{real}^{*} 4\right)$.

$\mathrm{y} 0$ : position of first row of data, in $\mathrm{km}\left(\mathrm{real}^{*} 4\right)$.

dy: delta y, spacing interval of rows, in $\mathrm{km}\left(\mathrm{real}{ }^{*}\right)$.

Data record: Each data record contains one row of scalar, real-valued data. The first word should contain the row coordinate, but in some programs this rule is not applied. In the data of this report, the first column is always "0". Subsequent words contain data: $f(1, j), f(2, j) \ldots f(n c o l, j)$, for the $j$-th row of data. The sort bit of FORTRAN code below is an example of grid input/output:

read or write (..) id,pgm,ncol,nrow,nz,x0,dx,y0,dy

do $10 \mathrm{j}=1$, nrow

10 read or write $(.$.$) y,(f(i,j),i=1,ncol)$

All grids are rectangular. Areas within the grid containing no data are flagged by dummy values (DVALS), normally $1.0 \mathrm{e}+38$. 


\section{REFERENCES}

Cordell, Lindrith, Phillips, J.D., and Godson, R.H., 1992, U.S. Geological Survey Potential-Field Geophysical Software Version 2.0, U.S. Geological Survey Open File Report 92-18.

Phillips, J.D., Duval, J.S., and Ambroziak, R.A., 1993, National Geophysical Data Grids; Gamma-ray, Gravity, Magnetic, and Topographic Data for the Conterminous United States: US Geological Survey digital data series DDS-9, 1 CD-ROM.

Pierce, Herbert A., 1994, Administrative report; Aeromagnetic data for the northern coast of Guyana: Presented to the Guyana Geologic Survey, Georgetown, Guyana, 4p. 4 Plates. 
Open-File Report 95-590-A and -B. Digital aeromagnetic anomaly data from eastern-most Guyana, By Herbert A. Pierce, Natalka Backjinski, and John-James Manes. 1995. 11p., seven

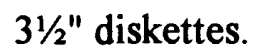

This report provides digital aeromagnetic data that were digitized as part of a continuing resource-assessment project of the Guyana Shield in northern-most Latin America. The data were digitized from 145 1:50,000-scale aeromagnetic contour maps and merged into a single data set. OF-94-590-A, documentation (11 p.); OF-590-B, contains compressed and backed up digitized aeromagnetic data on seven $3 \frac{1}{2}$ " diskettes (also includes a DOS text file copy of Part A).

Requirement for part B: IBM PC or compatible computer, MS DOS 6.2 or higher; math coprocessor suggested; at least $43 \mathrm{MB}$ of free hard disk space; suggest 386 with 387 coprocessor though 8088 and 8086 processors will work. 